\title{
AP-1, but not NF- $\kappa$ B, is required for efficient steroid-triggered cell death in Drosophila
}

\author{
M Lehmann ${ }^{1}$, C Jiang ${ }^{1,3}$, YT I $p^{2}$ and CS Thummel ${ }^{*, 1}$ \\ 1 Howard Hughes Medical Institute, Department of Human Genetics, 15 North \\ 2030 East Room 5100, University of Utah, Utah, UT 84112-5331, USA \\ 2 Program in Molecular Medicine, Department of Cell Biology, University of \\ Massachusetts Medical School, Worcester, Massachusetts, MA 01605, USA \\ ${ }^{3}$ Current address: California Institute of Technology, Division of Biology 216- \\ 76, HHMI, 1200 East California Blvd, Pasadena, CA 91125, USA \\ * Corresponding author: CS Thummel, University of Utah, Eccles Institute of \\ Human Genetics, 15 North 2030, Suite 5200, Salt Lake City, Utah, \\ UT 84112-5331, USA. Tel: +1 801581 2937; Fax: +1 801581 5374; \\ E-mail: Carl.thummel@genetics.utah.edu
}

Received 5.9.01; revised 10.10.01; accepted 13.11.01 Edited by G. Nunez

\begin{abstract}
Extensive studies in vertebrate cells have assigned a central role to Rel/NF- $k$ B and AP-1 family members in the control of apoptosis. We ask here whether parallel pathways might function in Drosophila by determining if Rel/NF- $\kappa$ B or AP-1 family members contribute to the steroid-triggered death of larval salivary glands during Drosophila metamorphosis. We show that two of the three Drosophila Rel/NF- $k$ B genes are expressed in doomed salivary glands and that one family member, Dif, is induced in a stage-specific manner immediately before the onset of programmed cell death. Similarly, Djun is expressed for many hours before salivary gland cell death while Dfos is induced in a stage-specific manner, immediately before this tissue is destroyed. We show that null mutations in the three Drosophila Rel/NF- $k$ B family members, either alone or in combination, have no apparent effect on this death response. In contrast, Dfos is required for the proper timing of larval salivary gland cell death as well as the proper induction of key death genes. This study demonstrates a role for AP-1 in the stage-specific steroidtriggered programmed cell death of larval tissues during Drosophila metamorphosis.

Cell Death and Differentiation (2002) 9, 581-590. DOI: 10.1038/ sj/cdd/4401003
\end{abstract}

Keywords: ecdysone; steroid hormone; metamorphosis; transcriptional regulation; autophagy

Abbreviations: JNKs, Jun N-terminal kinases; MAPK, MAP kinase, hid, head involution defective; RPR, Drosophila grim reaper

\section{Introduction}

Programmed cell death is a critical aspect of metazoan development, providing a means of removing obsolete or damaged cells and sculpting organs to assume their appropriate function. The regulation of programmed cell death is under precise spatial and temporal control in order to ensure that only obsolete or unnecessary cells are destroyed. Accordingly, multiple signal transduction systems act together to direct a programmed cell death response. Rel/NF- $\kappa$ B transcription factors function as critical downstream effectors of these death pathways. ${ }^{1,2}$ Rel/NF- $\kappa \mathrm{B}$ factors form homo- and heterodimers and are defined by the Rel homology domain, a region important for DNA binding, protein dimerization, interaction with cytoplasmic inhibitors, and nuclear translocation. ${ }^{2,3}$ Prior to their activation, Rel/NF$\kappa \mathrm{B}$ factors are restricted to the cytoplasm via interactions with $I \kappa B$ inhibitor proteins. A wide range of agents activate an $\mathrm{l} \kappa \mathrm{B}$ kinase complex that phosphorylates $\mathrm{I} \kappa \mathrm{B}$, leading to its degradation via a proteasome-mediated pathway. ${ }^{4}$ This, in turn, frees the Rel/NF- $\kappa \mathrm{B}$ factor, allowing it to translocate into the nucleus where it can activate target gene transcription. Rel/NF- $\kappa \mathrm{B}$ proteins can either inhibit or promote programmed cell death in a cell-type and signaldependent manner. ${ }^{1,5,6}$ Interestingly, these responses have been linked directly to the transcription of downstream effector genes. Thus, NF- $\kappa \mathrm{B}$ directly regulates a pro-survival $\mathrm{Bcl}$ family member in immune tissues where $\mathrm{NF}-\kappa \mathrm{B}$ prevents cell death, and NF- $\kappa \mathrm{B}$ directly regulates Fas ligand expression in $\mathrm{T}$ lymphocytes where this transcription factor drives activation-induced cell death. ${ }^{7-13}$

A number of studies have also implicated the AP-1 transcription factor as either a death inhibitor or death trigger depending on cellular context. ${ }^{9,14-16} \mathrm{AP}-1$ is a heterodimer of c-Jun and C-Fos. ${ }^{17}$ AP-1 activity is regulated by Jun $\mathrm{N}$-terminal kinases (JNKs) that phosphorylate specific serine residues in C-Jun. ${ }^{18} \mathrm{JNKs}$, in turn, integrate a wide range of upstream signaling events through MAP kinase (MAPK) signaling cascades. Growth factors can activate these pathways through interaction with $G$ proteincoupled receptors, and proinflammatory cytokines can activate MAPK through cell surface receptors. Extracellular stress such as irradiation, toxic drugs, or oxidative stress can also trigger the activation of AP-1 through JNK. ${ }^{16,19,20}$ The mechanisms by which divergent signals coordinate cellular responses through appropriate regulation of AP-1 activity remains a focus of current research.

Hormones also function as critical regulators of programmed cell death. ${ }^{21,22}$ For example, glucocorticoids regulate cell death in the central nervous system, sex steroids control cell death in the ovary, and progesterone can inhibit cell death in breast cancer cells. ${ }^{23-25}$ Steroid hormones have also been used for treatment of prostate and breast cancers ${ }^{26,27}$ and extensive efforts are underway to alter apoptotic signaling pathways in order to control other diseases, including viral infections, autoimmune diseases, and neurodegenerative disorders. ${ }^{28-30}$ 
We are studying the fruit fly, Drosophila melanogaster, as a model system for defining the hormonal regulation of programmed cell death. The Drosophila genome encodes homologs of all the major players defined in both $C$. elegans and mammalian cell death pathways, including TRAF, Bcl-2 family members, an Apaf/CED-4 homolog, seven caspase genes, and Inhibitor of Apoptosis (IAP) homologs. ${ }^{31-33}$ In addition, three key death inducer genes were defined in Drosophila, grim, reaper ( $r p r)$, and head involution defective (hid). ${ }^{34-36}$ These genes are necessary and sufficient for programmed cell death and appear to function in pairs to trigger the appropriate patterns of cell death during development. ${ }^{34-38}$ The expression of $r p r$ foreshadows cell death throughout Drosophila development, while hid and grim display close, but not exact correlation. HID activity can be regulated through the Ras pathway. ${ }^{39,40}$ Recent studies have indicated that the mammalian Smac/DIABLO proteins exert a similar function to rpr, hid, and grim, acting as key triggers of apoptosis by suppressing the ability of IAP proteins to inhibit caspase activation. $^{41,42}$ Thus, the basic components of the cell death machinery have been faithfully conserved through evolution, from worms and flies to humans.

Drosophila metamorphosis entails the simultaneous death of obsolete larval organs and the growth and differentiation of the adult fly, in response to sequential pulses of the steroid hormone 20-hydroxyecdysone (henceforth called ecdysone). ${ }^{43} \mathrm{~A}$ high titer ecdysone pulse at the end of larval development signals the destruction of the larval midgut and anterior muscles as the animal undergoes puparium formation, initiating metamorphosis and the prepupal stage of development. ${ }^{44}$ This is followed $\sim 10 \mathrm{~h}$ later by another ecdysone pulse that triggers the prepupal-pupal transition and the massive destruction of the larval salivary glands. Most salivary glands are destroyed rapidly in wild-type animals, at $\sim 15 \mathrm{~h}$ after puparium formation. ${ }^{45}$ Destruction of the larval midgut and salivary glands occurs by steroid-triggered autophagy with hallmark features of cell death, including permeability to the vital dye acridine orange, DNA fragmentation, and caspase activation. ${ }^{45-47}$ In addition, $r p r$ and hid are coordinately induced by ecdysone in a stage- and tissue-specific manner immediately before the onset of larval midgut and salivary gland cell death. ${ }^{45}$ Genetic studies have identified ecdysone-inducible transcription factors that direct rpr and hid induction in the doomed salivary glands. The zinc finger transcription factors encoded by the Broad-Complex and the E74A ETS domain transcription factor are required for rpr and hid induction. ${ }^{48}$ Similarly, the stage-specific ecdysone-inducible E93 gene is required for rpr and hid expression, along with the induction of several other key death regulators. ${ }^{49}$ Moreover, mutations in the $B R-C, E 74 A$, or E93 result in defects in larval salivary gland cell death. ${ }^{48,49}$ Finally, the ecdysone receptor directly induces $r p r$ transcription through a hormone response element in its promoter. $^{48}$

In this paper, we integrate Drosophila Rel/NF- $\kappa \mathrm{B}$ and AP-1 transcription factors into the ecdysone-triggered genetic hierarchy that directs larval salivary gland cell death. The Drosophila genome encodes three Rel/NF- $\kappa \mathrm{B}$ transcription factors, Dorsal, Dif, and Relish. Most homodimeric and heterodimeric combinations of these factors can regulate gene expression. ${ }^{50-53}$ Like their vertebrate homologs, these proteins can be inhibited by Drosophila $I_{\kappa} \mathrm{Bs}$, Cactus and the C-terminus of Relish. ${ }^{52,54,55}$ Dorsal is required for patterning the dorsal-ventral axis of the early embryo. ${ }^{52}$ As in vertebrates, the Cactus-Dorsal complex is restricted to the cytoplasm until signaling through the Toll receptor (related to the vertebrate interleukin-1 and Toll-like receptors) results in Cactus phosphorylation and degradation. ${ }^{52}$ This allows Dorsal to translocate to the nucleus where it can directly activate target gene transcription. In a further parallel with vertebrate Rel/NF- $\kappa$ B function, all three Drosophila family members are key regulators of Drosophila immunity to microbial infection. ${ }^{56-58}$ The striking conservation in the regulation and function of Drosophila $\mathrm{Rel} / \mathrm{NF}-\kappa \mathrm{B}$ family members raises the possibility that these proteins may also play a role in the control of programmed cell death.

Like its mammalian counterpart, Drosophila AP-1 is a heterodimer of Djun and Dfos transcription factors, and its activity is regulated by the Drosophila JNK. ${ }^{59-64}$ Unlike mammals, however, Dfos can function as a homodimer. ${ }^{59}$ Djun and Dfos are critical regulators of epithelial morphogenetic responses during both mid-embryogenesis and early metamorphosis. ${ }^{60-63,, 65-68}$

We show here that members of both of the Rel/NF- $\kappa \mathrm{B}$ and AP-1 families are induced in larval salivary glands in a stage-specific manner, immediately before the onset of cell death and in synchrony with rpr and hid induction. Although expression of a truncated Dif, with only the Rel homology domain, led to a significant delay in salivary gland cell death, extensive loss-of-function genetic studies did not uncover any direct role for the three Rel/NF- $\kappa$ B proteins in this death pathway. In contrast, we found that Dfos is required for efficient destruction of larval salivary glands as well as maximal levels of $r p r$ and hid transcription. This study demonstrates a role for Dfos in the steroid-triggered death of the Drosophila larval salivary glands during metamorphosis.

\section{Results}

\section{Rel/NF- $\kappa$ B and AP-1 transcripts are induced immediately before the onset of larval salivary gland cell death}

As a first step toward identifying a possible function for Drosophila Rel/NF- $\kappa \mathrm{B}$ and $\mathrm{AP}-1$ family members in programmed cell death, we set out to determine if these genes are expressed in larval salivary glands during the onset of metamorphosis. RNA was isolated from salivary glands dissected from staged late third instar larvae and prepupae and analyzed by Northern blot hybridization (Figure 1). Transcription of the E74A early ecdysone-inducible gene marks the two high titer pulses of ecdysone, in late third instar larvae and late prepupae. ${ }^{69}$ The second ecdysone-induced peak in E74A expression coincides with the coordinate induction of rpr and hid, consistent with the essential role of $E 74 A$ in hid induction and salivary gland cell death. ${ }^{48}$ Dorsal 


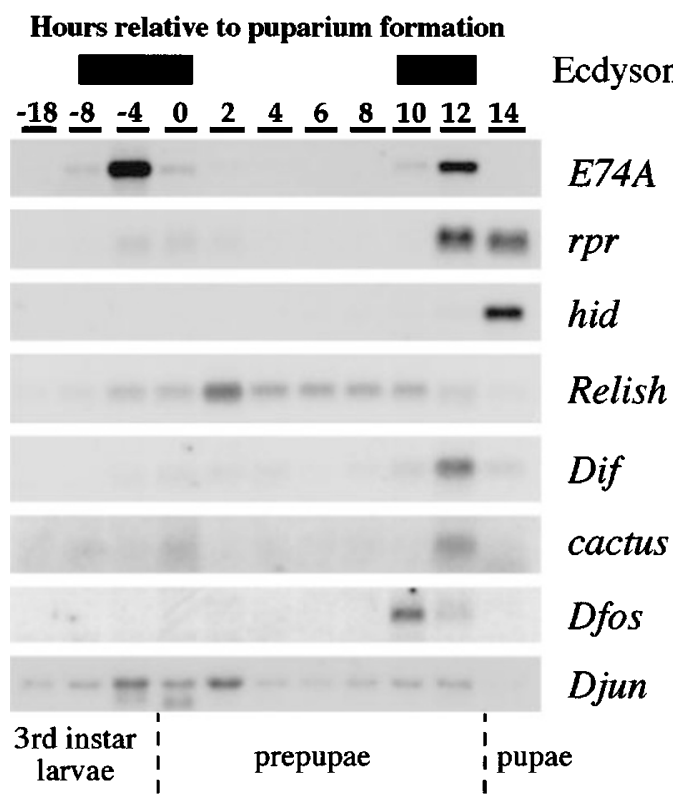

Figure 1 Temporal profiles of Rel/NF- $\kappa$ B and AP-1 gene expression before the onset of salivary gland cell death. RNA was isolated from the salivary glands of staged late third instar larvae, at either $\sim 18,8$, or $4 \mathrm{~h}$ before puparium formation, or from prepupae and pupae staged at $2 \mathrm{~h}$ intervals after puparium formation. Equal amounts of total RNA were fractionated by formaldehyde agarose gel electrophoresis and transferred to nylon. This blot was sequentially probed and stripped to detect E74A, rpr, hid, Relish, Dif, cactus, Dfos and Djun mRNA. The boxes at the top represent the peaks of the late larval and prepupal ecdysone pulses. Developmental stages are shown at the bottom

mRNA is not detectable at these stages in larval salivary glands (data not shown). In contrast, Relish mRNA is induced in parallel with the high titer late larval ecdysone pulse, peaks in $2 \mathrm{~h}$ prepupal salivary glands, and is then repressed in synchrony with the prepupal ecdysone pulse (Figure 1). Interestingly, Dif is induced as Relish is repressed, and expressed for a brief $2-4 \mathrm{~h}$ interval in late prepupal salivary glands, immediately before the onset of cell death (Figure 1). The Drosophila $\mathrm{I}_{\kappa} \mathrm{B}$ homolog cactus is expressed in parallel with Dif, indicating that other components of the Rel/NF- $\kappa \mathrm{B}$ signaling pathway are active at this time. Djun is expressed much like Relish. It is induced in late third instar larval salivary glands and then repressed in late prepupae (Figure 1). In contrast, Dfos is expressed in a stage-specific manner, in parallel with Dif, immediately before the onset of cell death (Figure 1). Thus, Dif and Dfos expression correlates well with the induction of rpr and hid, suggesting that these transcription factors might contribute to the ecdysone-triggered regulatory hierarchy that directs larval salivary gland cell death. Below we describe a series of experiments that test this hypothesis.

\section{Expression of a truncated Dif protein inhibits salivary gland cell death and impairs hid induction}

As an initial test of the role of Rel/NF- $\kappa$ B family members in salivary gland cell death, we used a transformant line that expresses a truncated form of Dif under the control of a heat- inducible promoter. This construct, referred to here as $\mathrm{P}[\mathrm{hs}$ $\operatorname{Dif}(R D)]$, directs expression of the Dif Rel homology domain but lacks the transactivation domain of this protein. $\mathrm{P}[\mathrm{hs}-$ $\operatorname{Dif}(R D)]$ prepupae were selected at $10.5 \mathrm{~h}$ after puparium formation, maintained at either $25^{\circ} \mathrm{C}$ or given a brief heat treatment, and then allowed to recover at room temperature for 3 or $5 \mathrm{~h}$. Salivary glands were dissected from these pupae and the levels of $r p r$ and hid transcription were determined by Northern blot hybridization (Figure 2). Transcription of $r p r$ is not significantly affected in salivary glands expressing $\operatorname{Dif}(R D)$, but hid transcription is reduced to approximately one-fifth of the control level (Figure 2). Consistent with this effect, $75 \%$ of the animals that express $\operatorname{Dif}(R D)$ had persistent salivary glands at $18 \mathrm{~h}$ after puparium formation $(n=12), 3 \mathrm{~h}$ after the destruction of salivary glands in control animals. These results suggest that Rel/NF- $\kappa \mathrm{B}$ family members may play a role in salivary gland cell death through the regulation of hid transcription.

$\mathrm{Rel} / \mathrm{NF}-\kappa \mathrm{B}$ family members are known to function as dimers, and the Rel domain is sufficient to mediate this interaction. ${ }^{50-53}$ Thus, the $\operatorname{Dif}(R D)$ construct could recruit an active Rel/NF- $\kappa \mathrm{B}$ family member to target promoters and thereby act in a manner similar to wild-type Dif, in spite of the absence of its activation domain. To test this possibility, we asked if ectopic overexpression of wild-type Dif would have a similar inhibitory effect on salivary gland cell death. Prepupae carrying both hs-GAL4 and UAS-Dif constructs were subjected to a single 30 min heat treatment at $38^{\circ} \mathrm{C}$ either 9 or $10 \mathrm{~h}$ after puparium formation, and persistent salivary glands were scored $9 \mathrm{~h}$ later. Of 49 animals examined, however, only one showed a detectable delay in salivary gland cell death. We thus conclude that Dif(RD) has a novel function that is distinct from that of wild-type Dif protein.

An alternate possibility is that the $\operatorname{Dif}(R D)$ construct is functioning as a dominant negative by preventing Rel/NF$\kappa \mathrm{B}$ family members from activating their normal targets in the genome. To test this possibility, we overexpressed a known dominant-negative regulator of Rel/NF- $\kappa \mathrm{B}$ signaling. Deletion of the $\mathrm{N}$-terminus of the Cactus protein results in a stable protein that holds Rel/NF- $\kappa$ B family members in the cytoplasm, rendering them unable to bind their genomic targets. ${ }^{55}$ We thus used either the hsp70 or a GAL4dependent promoter to express a truncated form of Cactus that is missing the coding region for the $\mathrm{N}$-terminal 125 amino acids. ${ }^{70}$ Constitutive expression of this protein in larval salivary glands using an appropriate GAL4 driver resulted in normal larval salivary gland cell death, with $6 \%$ of the $18 \mathrm{~h}$ pupae examined having persistent salivary glands $(n=34)$. This is similar to the $7 \%$ persistent salivary glands detected in $18 \mathrm{~h}$ pupae of the control genotype $(n=14)$. Heat-induced overexpression of the dominantnegative Cactus protein using a $30 \mathrm{~min} 38^{\circ} \mathrm{C}$ heat treatment at $10 \mathrm{~h}$ after puparium formation resulted in $11 \%$ of the $18 \mathrm{~h}$ pupae having persistent salivary glands $(n=28)$. Although this per cent is slightly higher than that seen with a constitutive GAL4 driver, it is within the range that is seen in heat-treated $w^{1118}$ control animals. Moreover, no reproducible effects were detected on either rpr or hid transcription by Northern blot analysis of salivary gland 
RNA (data not shown). We thus conclude that the Dif(RD) construct is not functioning in the same pathway as that regulated by the Cactus $\mathrm{I} \kappa \mathrm{B}$ inhibitor.

\section{Neither Dif nor Relish is required for hid induction in salivary glands}

Definitive proof of a role for Rel/NF- $\kappa$ B family members in larval salivary gland cell death requires an examination of null mutants in this pathway. Dorsal has no essential functions during zygotic development. It maps directly adjacent to Dif and, under certain conditions, can replace Dif function in the immune response. ${ }^{57,58}$ We thus analyzed the phenotypes associated with a deletion for both dorsal and Dif, Df(2L) J4. ${ }^{57}$ As a control for this study we examined the $d l^{P 01313}$ mutant,

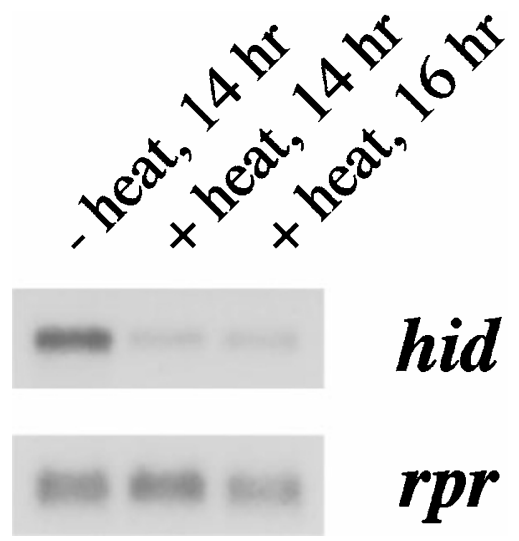

Figure 2 Ectopic expression of Dif(RD) results in reduced levels of hid transcription. $\mathrm{P}[\mathrm{hs}-\operatorname{Dif}(R D)] 10.5 \mathrm{~h}$ prepupae were maintained at either 25 or $37^{\circ} \mathrm{C}$ for $30 \mathrm{~min}$ and allowed to recover at $25^{\circ} \mathrm{C}$ for 3 or $5 \mathrm{~h}$. Salivary glands were dissected from these 14 and $16 \mathrm{~h}$ pupae and the levels of $r p r$ and hid mRNA were determined by Northern blot hybridization which specifically inactivates dorsal function. ${ }^{57}$ Salivary glands were dissected from staged homozygous $d^{P 01313}$ and $D f(2 L) J 4$ prepupae and expression of rpr and hid was determined by Northern blot hybridization (Figure 3A). Both death genes, however, are induced normally in $D f(2 L) J 4$ mutant pupae, indicating that Dif is not required for their expression. In addition, the timing of salivary gland cell death is normal in $D f(2 L) J 4$ mutant pupae (data not shown).

We also examined a possible contribution of Relish to programmed cell death because this Rel/NF- $\kappa \mathrm{B}$ family member is expressed in the larval salivary glands before they are destroyed (Figure 1). Salivary glands were dissected from staged Df(3R)E20 Relish mutant and control prepupae $^{56}$ and the expression of $r p r$ and hid was determined by Northern blot hybridization (Figure 3B). Again, this study revealed normal patterns of $r p r$ and hid induction, indicating that Relish is not required for death gene expression in doomed larval salivary glands. Moreover, cell death occurred normally in $D f(3 R) E 20$ mutant salivary glands (data not shown).

\section{There are no redundant functions between Drosophila Rel/NF- $\kappa$ B family members in salivary gland cell death}

One final possibility is that the three Drosophila Rel/NF- $\kappa \mathrm{B}$ family members could exert redundant functions in larval salivary gland cell death. Thus, for example, removing either Dif or Relish function alone might not reveal the role of a Rel/ $\mathrm{NF}-\kappa \mathrm{B}$ response in this pathway. Accordingly, we examined the phenotypes associated with a triple mutant that is missing all members of the Drosophila Rel/NF- $\kappa \mathrm{B}$ family. Animals carrying the $D f(2 L) J 4$ deletion were crossed to $D f(3 R) E 20$ animals and homozygotes were established for both deletions. Consistent with the expected weakness of this genetic background and, in particular, its susceptibility to infection,

A

Hours relative to

B puparium formation

\section{Hours relative to puparium formation}
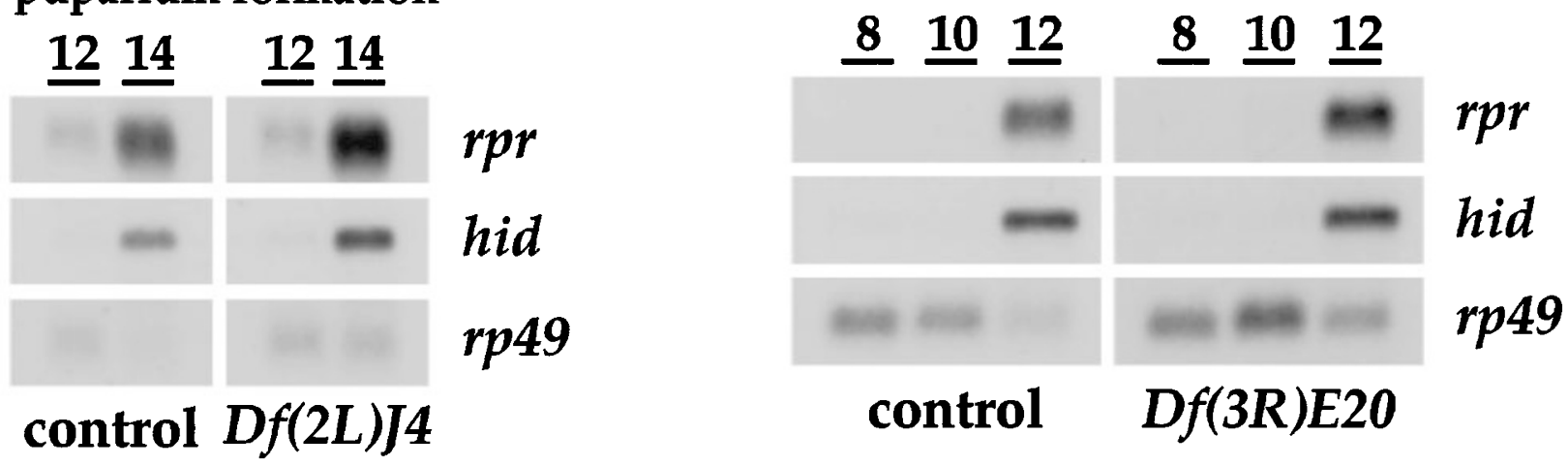

Figure 3 Dif and Relish mutations have no effect on rpr and hid transcription in doomed larval salivary glands. (A) Total RNA was isolated from salivary glands dissected from either control $d l^{P 01313}$ or $D f(2 L) J 412$ and $14 \mathrm{~h}$ pupae, and the levels of $r p r$ and hid mRNA were determined by Northern blot hybridization. Df(2L)J4 is a deletion mutation for both dorsal and Dif. ${ }^{57}$ Hybridization to detect $r p 49$ mRNA was used as a control for loading and transfer. (B) Total RNA was isolated from salivary glands dissected from either control E23 or $D f(3 R) E 208,10$ and $12 \mathrm{~h}$ pupae, and the levels of rpr and hid mRNA were determined by Northern blot hybridization. Df(3R)E20 is a null mutation for Relish. ${ }^{56}$ Hybridization to detect $r p 49 \mathrm{mRNA}$ was used as a control for loading and transfer. The $2 \mathrm{~h}$ difference in rpr and hid induction in panels $\mathbf{A}$ and $\mathbf{B}$ is consistent with the known differences in the timing of the prepupal ecdysone pulse in different genetic backgrounds ${ }^{87}$ 
very few of the triple mutants survived until puparium formation. Eleven such animals were selected, staged until 14.5 - $16 \mathrm{~h}$ after puparium formation, and their salivary glands were examined for signs of impending cell death. Of these animals, $18 \%$ had intact salivary glands, $18 \%$ had no salivary glands, and $64 \%$ had salivary glands that were being degraded. These numbers are comparable to those seen in wild-type animals at this stage in development indicating that there is no contribution of Rel/NF- $\kappa \mathrm{B}$ family members to larval salivary gland cell death.

To confirm the genetic identity of the stock we had established, RNA was isolated from the triple mutants and analyzed for Dif and Relish expression by Northern blot hybridization (Figure 4). As expected, control flies show normal levels of Dif and Relish (Figure 4, lanes 1,5). In

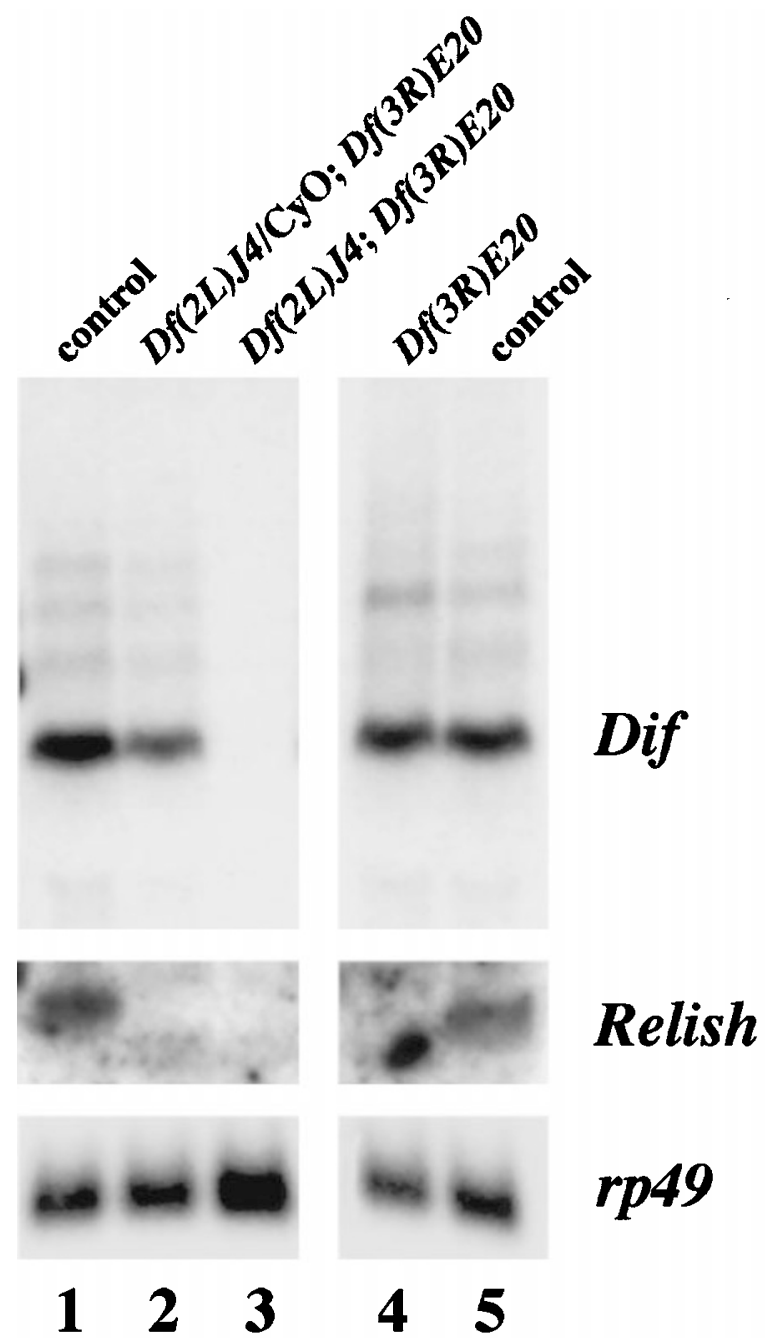

Figure 4 Dif and Relish are not expressed in Df(2L)J4; Df(3R)E20 mutants. RNA was isolated from adult flies of the depicted genotypes and Dif and Relish mRNA were detected by Northern blot hybridization. The control samples that express all Rel/NF- $\kappa$ B family members were derived from either $w^{1118}$ or E23 animals (lanes 1 and 5, respectively). Df(3R)E20 Relish mutants with either one copy (lane 2) or two copies (lane 4) of the dorsal and Dif genes were also tested, as was the $D f(2 L) J 4 ; D f(3 R) E 20$ double mutant that is missing all Rel/ NF- $\kappa$ B family members (lane 3 ). Hybridization to detect $r p 49$ mRNA was used as a control for loading and transfer addition, $D f(3 R) E 20$ mutants and $D f(3 R) E 20$ mutants that are missing one copy of the Dif locus lack Relish mRNA but continue to express Dif (Figure 4, lanes 2,4). Finally, flies carrying both homozygous deficiencies express neither Dif nor Relish (Figure 4, lane 3). These observations confirm the identity of the double deficiency stock and support the conclusion that Rel/NF- $\kappa \mathrm{B}$ family members are not required for salivary gland cell death.

\section{Dfos mutants display defects in larval salivary gland cell death as well as rpr and hid induction}

Both halves of the Drosophila AP-1 transcription factor, Dfos and Djun, are expressed in the salivary glands of late prepupae, with a brief burst of Dfos expression immediately preceding the induction of $r p r$ and hid (Figure 1). We therefore tested whether these factors might contribute to salivary gland cell death through regulating $r p r$ and/or hid transcription. Djun mutants die during embryogenesis and thus could not be used for this study. ${ }^{60-62}$ Similarly, most kay alleles lead to embryonic lethality. However, kay ${ }^{2}$ is a hypomorphic Dfos mutation that allows a few animals $(\sim 1 \%)$ to survive to adulthood, ${ }^{63,66}$ allowing us to analyze the role of Dfos in larval salivary gland cell death. Control kay ${ }^{2} / \mathrm{TM} 6 \mathrm{~B}$ pupae displayed no defects in salivary gland cell death, with glands either partially or completely destroyed by $16 \mathrm{~h}$ after puparium

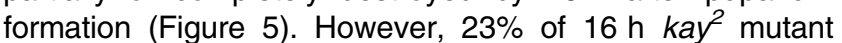

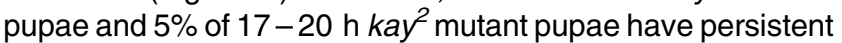
salivary glands (Figure 5). These kay ${ }^{2}$ mutants underwent ecdysone-triggered adult head eversion at approximately the same time as the control pupae, indicating that there is no overall effect on hormone signaling in this genetic background, or a general developmental delay. We thus conclude that Dfos is required for the proper timing of this death response.

The observed delay in the destruction of $k a y^{2}$ mutant larval salivary glands suggests that there might be a detectable effect on rpr and/or hid expression in this tissue. To test this possibility, salivary glands were isolated from staged kay²/TM6B control pupae at either 12 or $14 \mathrm{~h}$ after puparium formation and $k a y^{2}$ mutant pupae at 14 and $16 \mathrm{~h}$ after puparium formation. RNA was extracted from these tissues and the patterns of $r p r$ and hid transcription were analyzed by Northern blot hybridization (Figure 6A). Both $r p r$ and hid are induced normally in control salivary glands, and normal levels of rpr and hid mRNA are detected in $14 \mathrm{~h} \mathrm{kay^{2 }}$ mutant salivary glands (Figure 6A, lanes $1-3$ ). In salivary glands isolated from $16 \mathrm{~h} \mathrm{kay}^{2}$ mutants, however, little or no hid mRNA is detectable and the levels of rpr mRNA appear to be reduced (Figure 6A, lane 4). The absence of any effects on rpr and hid mRNA levels in $14 \mathrm{~h}$ $k a y^{2}$ mutant salivary glands is most likely due to the fact that many of these salivary glands would have died on time (Figure 5). In contrast, kay ${ }^{2}$ mutant glands that have survived to the $16 \mathrm{~h}$ timepoint, when all salivary glands from the control genotype have been destroyed (Figure 5), are more likely to reveal a role for Dfos in death gene expression.

To confirm this result, we used a salivary gland GAL4 driver to express a dominant negative form of Dfos, Fbz, in 


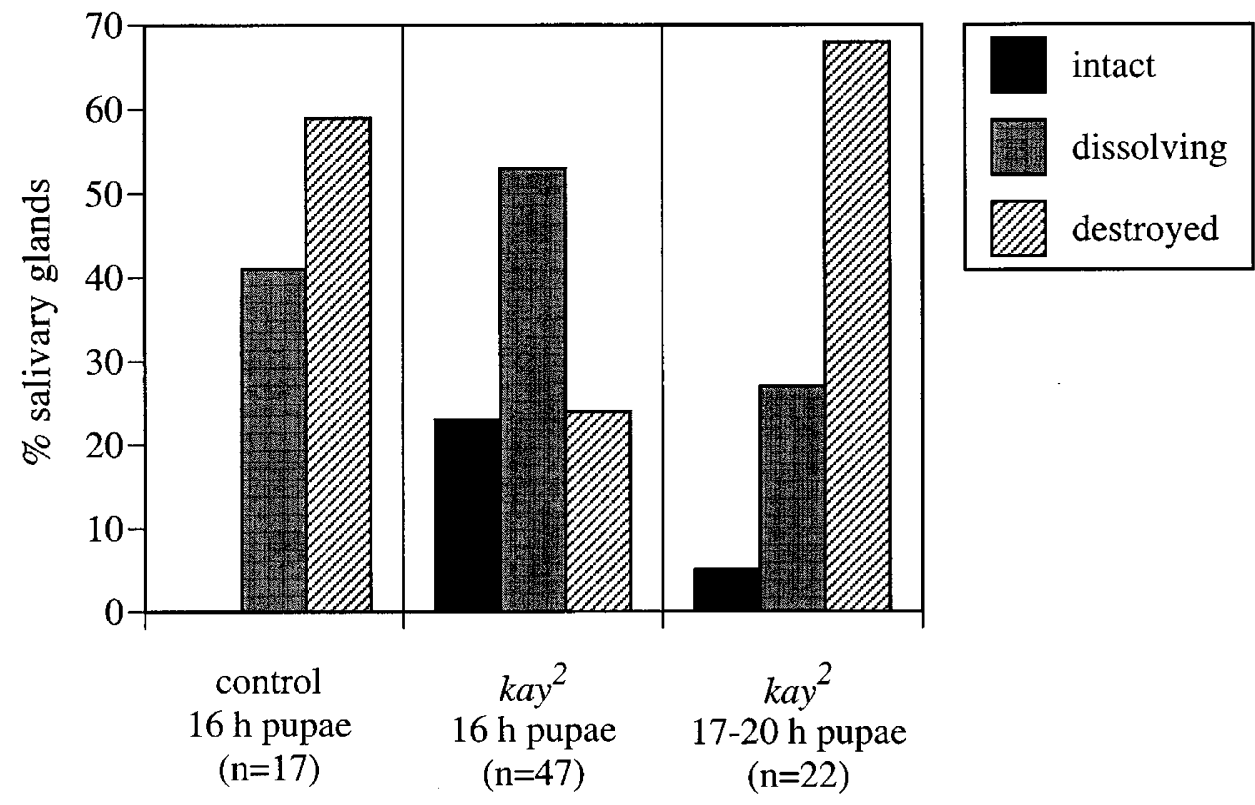

Figure 5 Salivary gland cell death is delayed in $\mathrm{kay}^{2}$ mutants. Salivary glands were dissected from either control kay $2 / \mathrm{TM} 6 \mathrm{~B} 16 \mathrm{~h}$ pupae, or $16 \mathrm{~h}$ and $17-20 \mathrm{~h}$ $\mathrm{kay}^{2}$ mutant pupae. $\mathrm{kay}^{2}$ mutant pupae that were delayed in their overall development were discarded. Fully intact, partially destroyed (dissolving), and completely destroyed salivary glands were scored for each genotype and the numbers are presented in graphic format
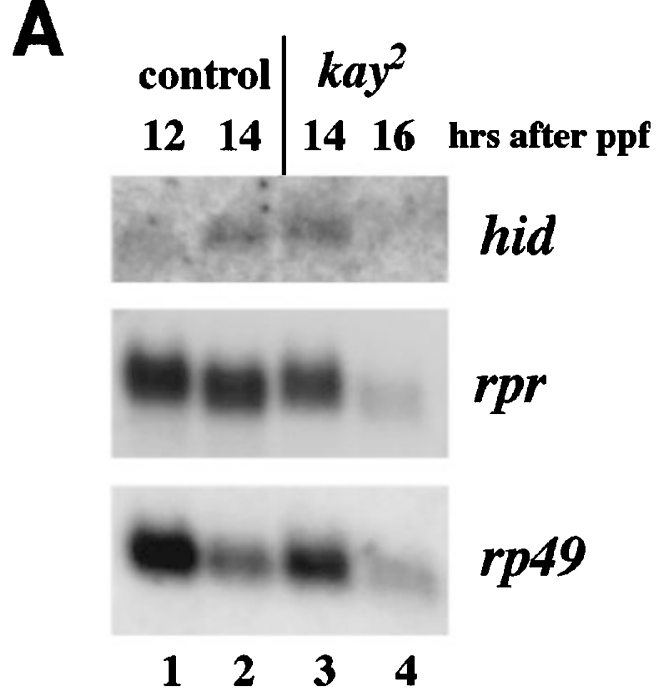

B

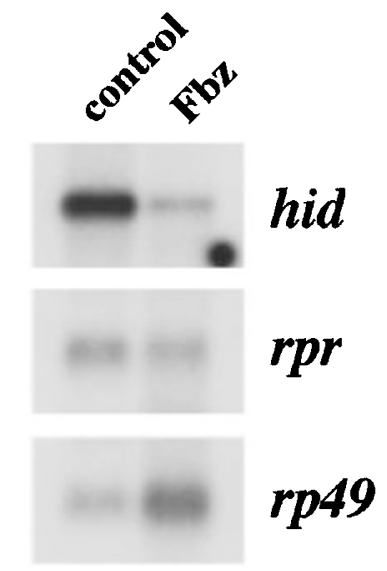

Figure 6 Reduced Dfos activity results in lower levels of rpr and hid transcription. (A) Total RNA was isolated from salivary glands of either kay ${ }^{2} / \mathrm{TM} 6 \mathrm{~B}$ control animals at 12 or $14 \mathrm{~h}$ after puparium formation (hours after ppf) or kay ${ }^{2}$ homozygotes at 14 or $16 \mathrm{~h}$ after puparium formation, and the levels of $r p r$ and hid mRNA were determined by Northern blot hybridization. Hybridization to detect rp49 mRNA was used as a control for loading and transfer. (B) Total RNA was isolated from $13 \mathrm{~h}$ pupae carrying either one copy of UAS-Fbz (control) or one copy of the D59 salivary gland GAL4 driver and one copy of the UAS-Fbz transgene (Fbz). The levels of $r p r$ and hid mRNA were determined by Northern blot hybridization. Hybridization to detect rp49 mRNA was used as a control for loading and transfer

the salivary glands of late prepupae. ${ }^{65}$ RNA was isolated from salivary glands at $13 \mathrm{~h}$ after puparium formation and the levels of rpr and hid mRNA were analyzed by Northern blot hybridization (Figure 6B). In agreement with the kay ${ }^{2}$ loss-of-function study, salivary glands expressing the dominant negative form of Dfos have reduced levels of hid mRNA. Moreover, correcting for the levels of the internal rp49 control, the levels of rpr mRNA also appear to be reduced. Similar results were seen in an independent duplicate experiment (data not shown). We thus conclude that Dfos is required for the proper timing of salivary gland cell death and that it exerts this effect by directing maximal levels of rpr and hid transcription.

\section{Discussion}

Several studies have shown that vertebrate steroid hormones can regulate programmed cell death through NF- $\kappa$ B and AP-1 
activity. ${ }^{71-75}$ In all of these cases, however, the downstream targets of NF- $\kappa \mathrm{B}$ and $\mathrm{AP}-1$ are not known, and thus it remains unclear how hormonal regulation of these transcription factors initiates a death response. In this study, we ask whether Rel/ $\mathrm{NF}-\kappa \mathrm{B}$ and/or AP-1 family members contribute to the steroidtriggered destruction of the larval salivary glands during Drosophila metamorphosis. Although we find no direct role for Rel/NF- $\kappa$ B family members in this pathway, we do show that $A P-1$ is required for efficient salivary gland cell death at the prepupal-pupal transition, and that it can mediate this effect through rpr and hid induction. This work provides a foundation for integrating AP-1 activity into the genetic cascade that controls larval salivary gland cell death during Drosophila metamorphosis.

\section{NF- $\kappa$ B and AP-1 family members are induced in a stage-specific manner before the onset of cell death}

Drosophila Rel/NF- $\kappa \mathrm{B}$ and $\mathrm{AP}-1$ family members all show some apparent regulation by ecdysone in doomed larval salivary glands. Both Relish and Djun are induced in late third instar larval glands, in synchrony with the E74A early ecdysone-inducible gene (Figure 1). Both peak in $2 \mathrm{~h}$ prepupae, are down-regulated in $4 \mathrm{~h}$ prepupae, and are repressed at $12-14 \mathrm{~h}$ after puparium formation, immediately following the prepupal ecdysone pulse. In contrast, Dif, cactus, and Dfos are all induced in a stage-specific manner, in synchrony with the prepupal ecdysone pulse and immediately preceding the induction of $r p r$ and hid and the onset of larval salivary gland cell death (Figure 1). Whereas Dif and cactus are induced in parallel with E74A, Dfos is expressed somewhat earlier, just as E74A and Dif mRNA are first detected (Figure 1). This early induction could be due to increased sensitivity of the Dfos promoter to ecdysone, resulting in induction by a lower hormone concentration than that required for $E 74 A{ }^{76}$

The stage-specific induction of Dif and Dfos provides a model for explaining the stage-specificity of rpr and hid expression in larval salivary glands. The rpr and hid death genes show no response to the late larval pulse of ecdysone but rather are selectively induced by the prepupal ecdysone pulse, $\sim 12 \mathrm{~h}$ after puparium formation (Figure 1). ${ }^{45}$ The similar stage-specific expression patterns of Dif and Dfos raise the possibility that these factors could direct the timing of $r p r$ and hid induction, providing a molecular mechanism whereby the repetitive ecdysone signal is refined into a stage-specific death response. We test this model and provide evidence of a role for Dfos in larval salivary gland cell death.

\section{A potential role for Rel/NF- $\kappa$ B binding sites in controlling hid expression and cell death}

We used five different genetic approaches to determine whether Rel/NF- $\kappa$ B family members might play a role in larval salivary gland cell death. These included ectopic expression of either wild-type Dif, a truncated form of Dif carrying only the DNA binding and dimerization domain, or a dominantnegative form of Cactus that should inactivate all NF- $\kappa \mathrm{B}$ responses. In addition we examined larval salivary gland cell death in loss-of-function mutants for either dorsal and Dif, Relish, or all three NF- $\kappa$ B family members. Of these, only ectopic expression of the truncated Dif protein resulted in a delay in larval salivary gland cell death and reduced levels of hid transcription (Figure 2). Unfortunately, the mechanism of action of this mutant form of Dif remains unclear. The absence of any clear effect on salivary gland cell death in the different mutant backgrounds, however, as well as in the presence of dominant-negative Cactus, strongly argues against a direct role for these transcriptional regulators in the salivary gland death response.

The observation that ectopic $\operatorname{Dif}(R D)$ expression can lead to death defects while no effect is seen in Rel/NF- $\kappa \mathrm{B}$ mutants argues that this truncated protein is functioning in a different pathway. One possibility is that $\operatorname{Dif(RD)}$ can occupy Rel/NF- $\kappa \mathrm{B}$ binding sites in hid regulatory sequences, thereby blocking the binding of other critical factors. These factors could either recognize the NF- $\kappa \mathrm{B}$ site directly or bind to an overlapping target sequence. The latter is more likely since we have tested all three genes predicted by the Drosophila genome sequence to have canonical Rel DNA binding domains - dorsal, Dif, and Relish. The presence of four optimal Rel/NF- $\kappa \mathrm{B}$ binding sites within a $28 \mathrm{~kb}$ region encompassing the $\sim 20 \mathrm{~kb}$ hid gene supports this model. It would be interesting to determine whether these sites are required for maximal hid induction by ecdysone. Regardless of the mechanism of $\operatorname{Dif}(\mathrm{RD})$ action, however, the key conclusion from this study is that Rel/NF- $\kappa \mathrm{B}$ family members are not required for the steroid-triggered cell death of larval salivary glands during Drosophila metamorphosis.

Morphological and genetic studies have demonstrated that Drosophila larval salivary glands die by autophagy rather than apoptosis. ${ }^{46,47}$ Autophagy is characterized by the formation of multiple acidic autophagic vacuoles within the doomed cells followed by massive cellular degeneration. Studies in vertebrate cells have shown that Rel/NF- $\kappa \mathrm{B}$ and AP-1 family members play a critical role in controlling apoptosis. ${ }^{1,5,6,9,14-16}$ No studies, however, have addressed a possible role for these factors in autophagic cell death. The results of this work indicate that Rel/NF- $\kappa \mathrm{B}$ family members have no function in at least one autophagic death response, and suggest that the activity of this pathway may be specific to apoptotic programmed cell death. Further studies of Rel/NF- $\kappa$ B function in other autophagic death responses should provide insight into its role in regulating programmed cell death during development.

\section{Dfos is required for efficient larval salivary gland cell death}

In contrast to our results with $\mathrm{Rel} / \mathrm{NF}-\kappa \mathrm{B}$ family members, we find that the Drosophila homolog of Fos is required for maximal rpr and hid transcription as well as the proper timing of larval salivary gland cell death. Intact larval salivary glands can be detected in 16-20 h $\mathrm{kay}^{2}$ mutant pupae, a time when glands in the control genotype have all entered cell death (Figure 5). In addition, the levels of both rprand hid are reduced in persistent kay ${ }^{2}$ mutant salivary glands (Figure $6 \mathrm{~A}$, lane 4 ) as well as 
salivary glands that express a dominant negative form of $D f o s$ (Figure 6B). It is important to note, however, that this is a

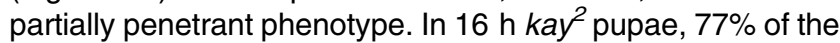
larval salivary glands are either completely or partially destroyed, and only $5 \%$ of the salivary glands persist until $17-20 \mathrm{~h}$ after puparium formation (Figure 5 ). This is similar to the partial salivary gland death defects observed in $E 74 A$ mutants and supports the proposal that multiple independent pathways are required to direct efficient larval salivary gland cell death. ${ }^{48}$ We thus conclude that Dfos is required for directing efficient larval salivary gland cell death in response to the prepupal pulse of ecdysone. It is interesting to note that there are three AP-1 binding sites in the $7 \mathrm{~kb}$ region of the $r p r$ promoter that confers maximal expression, suggesting that Dfos may directly regulate death gene expression.

Ecdysone triggers two apparently opposite biological responses at the onset of metamorphosis - the death of larval tissues and the growth and differentiation of adult tissues. ${ }^{77}$ It is interesting to note that AP-1 functions in both of these pathways. The late larval ecdysone pulse triggers morphogenesis of the leg and wing imaginal discs resulting in the formation of rudimentary adult appendages. ${ }^{78}$ The thoracic portions of the wing discs then fuse during prepupal development to form a smooth intact thorax that is evident on the dorsal surface of the adult fly. This fusion is dependent on AP-1 signaling. ${ }^{67,68}$ Thus, it appears that AP-1 exerts distinct stage- and tissue-specific functions during the onset of metamorphosis. Initially required for fusion of the thoracic imaginal discs, AP-1 is later required for efficient destruction of the larval salivary glands in response to ecdysone.

It is interesting to note that the results reported here for Dfos in larval salivary gland cell death are similar to those seen in mice. The expression of c-Fos precedes programmed cell death during normal mouse development. ${ }^{79}$ In spite of this correlation, however, mutant mice lacking c-Jun alone or c-Jun and c-Fos show only minor effects on programmed cell death responses. ${ }^{80,81}$ But, unlike Drosophila, the presence of multiple AP-1 family members encoded by the mouse genome complicates the interpretation of these results. Further functional studies of AP-1 should provide a better understanding of its roles in regulating programmed cell death during fly and mouse development.

\section{Materials and Methods}

\section{Drosophila stocks}

Canton $S$ was used as a wild-type stock. The $d l^{P 01313}$ dorsal mutant and $D f(2 L) J 4 d l$, Dif double mutant stocks ${ }^{57}$ were maintained as $y w$, $d^{P 01313} / C y o, y+$ and $y w, D f(2 L) J 4 / C y o, y+$ or Df(2L)J4/Cyo GFP. Homozygous $\mathrm{dl}^{P 01313}$ and $D f(2 L) J 4$ mutant third instar larvae were identified by their yellow mouth hooks. The Relish mutant $D f(3 R) E 20$ and its control line E23 have been described and were kindly provided by Dan Hultmark. E23 is a precise excision of a $\mathrm{P}$ element inserted in the $5^{\prime}$ end of the Relish gene. ${ }^{56} \mathrm{Df}(3 R) E 20$ is an imprecise excision of this $\mathrm{P}$ element that removes all four Relish transcription start sites and some $5^{\prime}$ untranslated sequences. ${ }^{56}$ Both E23 and Df(3R)E20 are homozygous viable. The GAL4/UAS system was used to direct ectopic expression in larval salivary glands. ${ }^{82}$ hs-GAL4 transformants were obtained from the Bloomington stock center. D59 was used to drive GAL4-dependent expression in larval salivary glands. ${ }^{83}$ The dominant negative cactus BP4- $\triangle \mathrm{N} 125$ cact $\triangle \mathrm{PEST}$ cDNA was kindly provided by D Stein, ${ }^{70}$ the kay $^{2}$ mutant stock was provided by D Bohmann ${ }^{63}$ and UAS-Fbz transformants were provided by M Bienz. ${ }^{65}$

\section{Developmental staging}

Late third instar larvae were staged by maintaining them on food containing $0.1 \%$ bromophenol blue, as described. ${ }^{84}$ Blue gut mid-third instar larvae are referred as $-18 \mathrm{~h}$ relative to puparium formation, partially clear gut late third instar larvae are referred to as $-8 \mathrm{~h}$, and clear gut late third instar larvae are referred to as $-4 \mathrm{~h}$. Prepupae and pupae were staged relative to puparium formation $(0 \mathrm{~h})$ as described. $^{84}$

\section{Ectopic expression studies}

The P[hs-Dif(RD)] construct was generated by cutting the Dif cDNA with Ndel (artificially generated at codon 16) ${ }^{53}$ and EcoRV (at codon 432). The $1.25 \mathrm{~kb}$ fragment was inserted into the Stul site of the pCaSpeR-hs vector by blunt end ligation. This construct removes the C-terminal 235 amino acids of Dif which should function as the transcriptional activation domain. This construct was introduced into $y w^{67}$ flies by $P$ element-mediated germline transformation. ${ }^{85}$ To ectopically express $\operatorname{Dif}(\mathrm{RD}), \mathrm{P}[h s-\operatorname{Dif}(R D)]$ transformants were synchronized at puparium formation and allowed to develop at $25^{\circ} \mathrm{C}$ for $10.5 \mathrm{~h}$. They were incubated in a $37^{\circ} \mathrm{C}$ water bath for $30 \mathrm{~min}$, and allowed to recover at $25^{\circ} \mathrm{C}$ for 3 or $5 \mathrm{~h}$, after which their salivary glands were dissected. As a control, transformants were selected at puparium formation and allowed to develop at $25^{\circ} \mathrm{C}$ for $14 \mathrm{~h}$ before salivary glands were dissected. Total RNA was then extracted from the salivary glands and analyzed by Northern blot hybridization. The cactus $\triangle \mathrm{N} 125$ cact $\triangle \mathrm{PEST} \mathrm{cDNA}^{70}$ was inserted into both pCaSpeR-hsact and pUAST. The vectors were cut with EcoRI, filled-in, and then cut with Notl, and the $\Delta \mathrm{N} 125$ cact $\triangle \mathrm{PEST}$ cDNA was inserted as a $1.5 \mathrm{~kb}$ HindllI (filled-in)-Notl fragment. Transgenic lines were established for these constructs by $\mathrm{P}$ element-mediated germline transformation of the recipient strain $w^{1118}$.

\section{Northern blot hybridization}

Total RNA isolated from 12 pairs of dissected salivary glands was fractionated by formaldehyde gel electrophoresis and transferred to nylon membranes as described. ${ }^{69}$ For analysis of the $\mathrm{dl}$, Dif, and Relish triple mutant (Figure 4), $20 \mu \mathrm{g}$ total RNA from adult flies was loaded per lane. Each blot was sequentially hybridized with one or more radioactive probes and stripped for rehybridization. ${ }^{69}$ The $E 74 A$ and $r p 49$ probes were prepared as described; ${ }^{86} \mathrm{rpr}$ and hid probes were prepared as described. ${ }^{45}$ The following DNA fragments were used to detect Djun, Dfos, Relish, Dif and cactus - Djun: a $300 \mathrm{bp}$ fragment corresponding to the coding region for the first 100 amino acids of the Djun protein; Dfos: a 1195 bp BamHI fragment; Relish: an $804 \mathrm{bp} \mathrm{BamHI-Hindlll}$ fragment; Dif: an 855 bp BamHI-EcoRI fragment; cactus: an 1162 bp Bgll fragment.

\section{Acknowledgements}

We thank D Hultmark for providing the E23 control and Df(3R)E20 Relish mutant, D Stein for providing the cactus $\Delta 125$ construct, D Bohmann for the 
$k a y^{2}$ mutant, M Bienz for the UAS-Fbz stock, and the Bloomington Stock Center for providing GAL4 driver stocks. M Lehmann is the recipient of a research fellowship (Le870/4-1) from the Deutsche Forschungsgemeinschaft. This work was supported by National Institutes of Health grant RO1 GM53269 to YT Ip and RO1 GM60954 to CS Thummel.

\section{References}

1. Van Antwerp D, Martin S, Verma l and Green DR (1998) Inhibition of TNF-induced apoptosis by NF- $\kappa$ B. Trends Cell. Biol. 8: 107-111

2. Mercurio F and Manning AM (1999) Multiple signals converging on NF- $\kappa$ B. Curr. Biol. 11: 226-232

3. Baeuerle PA and Baltimore D (1996) NF- $\kappa B$ : ten years after. Cell 87: 13-20

4. May MJ and Ghosh S (1997) NF- $\kappa$ B and $I_{\kappa} B$ proteins: An overview. Semin. Cancer Biol. 8: 63-73

5. Foo S and Nolan G (1999) NF-kB to the rescue: RELs, apoptosis and cellular transformation. Trends Genet. 15: 229-235

6. Baichwal VR and Baeuerle PA (1997) Activate NF-kappa B or die? Curr. Biol. 7: R94-R96

7. Chen C, Edelstein LC and Gélinas C (2000) The Rel/NF- $k B$ family directly activates expression of the apoptosis inhibitor Bcl- $x_{L}$. Mol. Cell. Biol. 20: $2687-$ 2695

8. Grumont RJ, Rourke IJ and Gerondakis S (1999) Rel-dependent induction of A1 transcription is required to protect $B$ cells from antigen receptor ligand-induced apoptosis. Genes Dev. 13: 400-411

9. Kasibhatla S, Brunner T, Genestier L, Echeverri F, Mahboubi A and Green DR (1998) DNA damaging agents induce expression of Fas ligand and subsequent apoptosis in T lymphocytes via the activation of NF- $\kappa$ B and AP-1. Mol. Cell. 1: $543-551$

10. Kasibhatla S, Genestier L and Green DR (1999) Regulation of Fas-ligand expression during activation-induced cell death in $\mathrm{T}$ lymphocytes via nuclear factor $\kappa$ B. J. Biol. Chem. 274: 987-992

11. Matsui K, Fine A, Zhu B, Marshak-Rothstein A and Ju ST (1998) Identification of two NF- $\kappa$ B sites in mouse CD95 ligand (Fas ligand) promoter: functional analysis in T cell hybridoma. J. Immunol. 161: 3469-3473

12. Schneider A, Martin-Villalba A, Weih F, Vogel J, Wirth T and Schwaninger M (1999) NF- $k$ B is activated and promotes cell death in focal cerebral ischemia. Nat. Med. 5: $554-559$

13. Zong WX, Edelstein LC, Chen C, Bash J and Gelinas C (1999) The prosurvival $\mathrm{Bcl}-2$ homolog Bfl-1/A1 is a direct transcriptional target of NF- $\kappa \mathrm{B}$ that blocks TNF $\alpha$-induced apoptosis. Genes Dev. 13: 382-387

14. Herdegen T, Skene P and Bahr M (1997) The c-Jun transcription factorbipotential mediator of neuronal death, survival and regeneration. Trends Neurosci. 20: $227-231$

15. Jehn BM and Osborne BA (1997) Gene regulation associated with apoptosis. Crit. Rev. Eukaryot. Gene Expr. 7: 179-193

16. Tournier C, Hess P, Yang D, Xu J, Turner T, Nimnual A, Bar-Sagi D, Jones S, Flavell R and Davis R (2000) Requirement of JNK for stress-induced activation of the cytochrome c-mediated death pathway. Science 288: 870-874

17. Karin M, Liu Z and Zandi E (1997) AP-1 function and regulation. Curr. Opin. Cell. Biol. 9: 240-246

18. Davis RJ (2000) Signal transduction by the JNK group of MAP kinases. Cell 103 : 239-252

19. Basu S and Kolesnick R (1998) Stress signals for apoptosis: ceramide and c-Jun kinase. Oncogene 17: $3277-3285$

20. Verheij M, Bose R, Lin XH, Yao B, Jarvis WD, Grant S, Birrer MJ, Szabo E, Zon LI, Kyriakis JM, Haimovitz-Friedman A, Fuks Z and Kolesnick RN (1996) Requirement for ceramide-initiated SAPK/JNK signalling in stress-induced apoptosis. Nature 380: 75-79

21. Evans-Storms RB and Cidlowski JA (1995) Regulation of apoptosis by steroid hormones. J. Steroid Biochem. Mol. Biol. 53: $1-8$

22. Kiess W and Gallaher B (1998) Hormonal control of programmed cell death/ apoptosis. Eur. J. Endocrinol. 138: 482-491

23. Chun SY, Eisenhauer KM, Minami S, Billig H, Perlas E and Hsueh AJ (1996) Hormonal regulation of apoptosis in early antral follicles: follicle-stimulating hormone as a major survival factor. Endocrinology 137: 1447-1456
24. Gould E and Cameron HA (1996) Regulation of neuronal birth, migration and death in the rat dentate gyrus. Dev. Neurosci. 18: 22-35

25. Michna H, Nishino Y, Neef G, McGuire WL and Schneider MR (1992) Progesterone antagonists: tumor-inhibiting potential and mechanism of action. J. Steroid Biochem. Mol. Biol. 41: 339-348

26. Moss HB (1992) Endocrine therapy for advanced breast cancer: a review. Breast Cancer Res. Treat. 21: 15-26

27. Schulman CC (1994) Neoadjuvant androgen blockade prior to prostatectomy: a retrospective study and critical review. Prostate 5(Suppl) 9-14

28. Gibbons GH and Dzau VJ (1996) Molecular therapies for vascular diseases. Science 272: 689-693

29. Rudin CM and Thompson CB (1997) Apoptosis and disease: regulation and clinical relevance of programmed cell death. Annu. Rev. Med. 48: 267-281

30. Thompson CB (1995) Apoptosis in the pathogenesis and treatment of disease. Science 267: $1456-1462$

31. Abrams JM (1999) An emerging blueprint for apoptosis in Drosophila. Trends Cell. Biol. 9: 435-440

32. Aravind L, Dixit VM and Koonin EV (2001) Apoptotic molecular machinery: vastly increased complexity in vertebrates revealed by genome comparisons. Science 291: $1279-1284$

33. Bangs $P$ and White K (2000) Regulation and execution of apoptosis during Drosophila development. Dev. Dyn. 218: 68-79

34. Chen P, Nordstrom W, Gish B and Abrams JM (1996) grim, a novel cell death gene in Drosophila. Genes Dev. 10: 1773-1782

35. Grether ME, Abrams JM, Agapite J, White K and Steller H (1995) The head involution defective gene of Drosophila melanogaster functions in programmed cell death. Genes Dev. 9: 1694-1708

36. White K, Grether ME, Abrams JM, Young L, Farrell Kand StellerH (1994) Genetic control of programmed cell death in Drosophila. Science 264: 677-683

37. Robinow S, Draizen T and Truman J (1997) Genes that induce apoptosis: Transcriptional regulation in identified, doomed neurons of the Drosophila CNS. Dev. Biol. 190: 206-213

38. Zhou L, Schnitzler A, Agapite J, Schwartz LM, Steller H and Nambu JR (1997) Cooperative functions of the reaper and head involution defective genes in the programmed cell death of Drosophila central nervous system midline cells. Proc. Natl. Acad. Sci. USA 94: 5131-5136

39. Bergmann A, Agapite J, McCall Kand Steller H(1998) The Drosophilagene hid is a direct molecular target of Ras-dependent survival signaling. Cell 95: 331-341

40. Kurada $P$ and White K (1998) Ras promotes cell survival in Drosophila by downregulating hid expression. Cell 95: 319-329

41. Chai J, Du C, Wu JW, Kyin S, Wang X and Shi Y (2000) Structural and biochemical basis of apoptotic activation by Smac/DIABLO. Nature 406: $855-$ 862

42. Ekert P, Silke J, Hawkins C, Verhagen A and Vaux D (2001) Diablo promotes apoptosis by removing MIHA/XIAP from processed caspase 9. J. Cell. Biol. 152: $483-490$

43. Riddiford LM (1993) Hormones and Drosophila development. In The Development of Drosophila melanogaster, Bate M and Martinez Arias A, eds (Cold Spring Harbor, NY: Cold Spring Harbor Laboratory Press) pp. 899-940

44. Robertson CW (1936) The metamorphosis of Drosophila melanogaster, including an accurately timed account of the principal morphological changes. J. Morph. 59: 351-399

45. Jiang C, Baehrecke EH and Thummel CS (1997) Steroid regulated programmed cell death during Drosophila metamorphosis. Development 124: 4673-4683

46. Lee CY and Baehrecke $\mathrm{EH}$ (2001) Steroid regulation of autophagic programmed cell death during development. Development 128: 1443-1455

47. von Gaudecker B and Schmale EM (1974) Substrate-histochemical investigations and ultrahistochemical demonstrations of acid phosphatase in larval and prepupal salivary glands of Drosophila melanogaster. Cell Tiss. Res. 155: $75-$ 89

48. Jiang C, Lamblin A-F, Steller H and Thummel CS (2000) A steroid-triggered transcriptional hierarchy controls salivary gland cell death during Drosophila metamorphosis. Mol. Cell. 5: 445-455

49. LeeCY,WendelDP, Reid P, Lam G, ThummelCS and BaehreckeEH(2000)E93 directs steroid-triggered programmed cell death in Drosophila. Mol. Cell. 6:433443

50. Han ZS and Ip YT (1999) Interaction and specificity of Rel-related proteins in regulating Drosophila immunity gene expression. J. Biol. Chem. 274: 2135521361 
51. Dushay MS, Asling B and Hultmark D (1996) Origins of immunity: Relish, a compound Rel-like gene in the antibacterial defense of Drosophila. Proc. Natl. Acad. Sci. USA 93: 10343-10347

52. Belvin MP and Anderson KV (1996) A conserved signaling pathway: the Drosophila toll-dorsal pathway. Annu. Rev. Cell. Dev. Biol. 12: 393-416

53. Ip YT, Reach M, Engstrom Y, Kadalayil L, CaiH, Gonzalez-Crespo S, TateiKand Levine M (1993) Dif, a dorsal-related gene that mediates an immune response in Drosophila. Cell 75: 753-763

54. Stöven S, Ando I, Kadalayil L, Engström Y and Hultmark D (2000) Activation of the Drosophila NF- $k$ B factor Relish by rapid endoproteolytic cleavage. EMBO Rep. 1: 347-352

55. Belvin MP, Jin Y and Anderson KV (1995) Cactus protein degradation mediates Drosophila dorsal-ventral signaling. Genes Dev. 9: 783-793

56. Hedengren M, Asling B, Dushay MS, Ando I, Ekengren S, Wihlborg M and Hultmark D (1999) Relish, a central factor in the control of humoral but not cellular immunity in Drosophila. Mol. Cell. 4: 827-837

57. Meng X, Khanuja BS and Ip YT (1999) Toll receptor-mediated Drosophila immune response requires Dif, an NF- $\kappa$ B factor. Genes Dev. 13: 792-797

58. Rutschmann S, Jung AC, Hetru C, Reichhart JM, Hoffmann JA and Ferrandon D (2000) The Rel protein DIF mediates the antifungal but not the antibacterial host defense in Drosophila. Immunity 12: 569-580

59. Perkins KK, Admon A, Patel N and Tjian R (1990) The Drosophila Fos-related AP-1 protein is a developmentally regulated transcription factor. Genes Dev. 4 : $822-834$

60. Sluss HK, Han Z, Barrett T, Goberdhan DC, Wilson C, Davis RJ and Ip YT (1996) A JNK signal transduction pathway that mediates morphogenesis and an immune response in Drosophila. Genes Dev. 10: 2745-2758

61. Hou XS, Goldstein ES and Perrimon N (1997) Drosophila Jun relays the Jun amino-terminal kinase signal transduction pathway to the Decapentaplegic signal transduction pathway in regulating epithelial cell sheet movement. Genes Dev. 11: 1728-1737

62. Kockel L, Zeitlinger J, Staszewski LM, Mlodzik M and Bohmann D (1997) Jun in Drosophila development: redundant and nonredundant functions and regulation by two MAPK signal transduction pathways. Genes Dev. 11: 1748-1758

63. Zeitlinger J, Kockel L, Peverali FA, Jackson DB, Mlodzik M and Bohmann D (1997) Defective dorsal closure and loss of epidermal decapentaplegic expression in Drosophila fos mutants. EMBO J. 16: 7393-7401

64. Riesgo-Escovar JR, Jenni M, Fritz A and Hafen E (1996) The Drosophila Jun-Nterminal kinase is required for cell morphogenesis but not for DJun-dependent cell fate specification in the eye. Genes Dev. 10: 2759-2768

65. Eresh S, Riese J, Jackson DB, Bohmann D and Bienz M (1997) A CREB-binding site as a target for decapentaplegic signalling during Drosophila endoderm induction. EMBO J. 16: 2014-2022

66. Riesgo-Escovar JR and Hafen E (1997) Common and distinct roles of DFos and DJun during Drosophila development. Science 278: 669-672

67. Agnes F, Suzanne M and Noselli S (1999) The Drosophila JNK pathway controls the morphogenesis of imaginal discs during metamorphosis. Development 126: 5453-5462

68. Zeitlinger J and Bohmann D (1999) Thorax closure in Drosophila: involvement of Fos and the JNK pathway. Development 126: 3947-3956

69. Karim FD and Thummel CS (1991) Ecdysone coordinates the timing and amounts of $E 74 A$ and $E 74 B$ transcription in Drosophila. Genes Dev. 5: $1067-$ 1079

70. Bergmann A, Stein D, GeislerR, Hagenmaier S, Schmid B, Fernandez N, Schnell $B$ and Nüsslein-Volhard C (1996) A gradient of cytoplasmic Cactus degradation establishes the nuclear localization gradient of the dorsal morphogen in Drosophila. Mech. Dev. 60: 109-123
71. Cerillo G, Rees A, Manchanda N, Reilly C, Brogan I, White A and Needham M (1998) The oestrogen receptor regulates NF- $\kappa$ B and AP-1 activity in a cellspecific manner. J. Steroid Biochem. Mol. Biol. 67: 79-88

72. Ivanov VN and Nikolic-Zugic J (1997) Transcription factor activation during signal-induced apoptosis of immature CD4(+)CD8(+) thymocytes. A protective role of c-Fos. J. Biol. Chem. 272: 8558-8566

73. McKay LI and Cidlowski JA (1998) Cross-talk between NF- $\kappa$ B and the steroid hormone receptors: mechanisms of mutual antagonism. Mol. Endocrinol. 12: $45-56$

74. Wissink S, van Heerde EC, vand der Burg B and van der Saag PT (1998) A dual mechanism mediates repression of NF- $\kappa \mathrm{B}$ activity by glucocorticoids. Mol. Endocrinol. 12: 355-363

75. Zhou F and Thompson EB (1996) Role of $c$-jun induction in the glucocorticoidevoked apoptotic pathway in human leukemic lymphoblasts. Mol. Endocrinol. 10: $306-316$

76. Karim FD and Thummel CS (1992) Temporal coordination of regulatory gene expression by the steroid hormone ecdysone. EMBO J. 11: 4083-4093

77. Bodenstein D (1965) The postembryonic development of Drosophila. In Biology of Drosophila, Demerec M, ed. (New York: Hafner Publishing Co.) pp. 275-367

78. Fristrom D and Fristrom JW (1993) The metamorphic development of the adult epidermis. In The Development of Drosophila melanogaster. Bate M and Martinez Arias A, ed. (Cold Spring Harbor, NY: Cold Spring Harbor Laboratory Press) pp. 843-897

79. Smeyne RJ, Vendrell M, Hayward M, Baker SJ, Miao GG, Schilling K, Robertson LM, Curran T and Morgan JI (1993) Continuous c-fos expression precedes programmed cell death in vivo. Nature 363: 166-169

80. EferlR, Sibilia M, Hilberg F, Fuchsbichler A, Kufferath I, Guertl B, Zenz R, Wagner EF and Zatloukal K (1999) Functions of c-Jun in liver and heart development. J. Cell. Biol. 145: 1049-1061

81. Roffler-Tarlov S, Brown JJ, Tarlov E, Stolarov J, Chapman DL, Alexiou M and Papaioannou VE (1996) Programmed cell death in the absence of c-Fos and cJun. Development 122: 1-9

82. Brand AH and Perrimon N (1993) Targeted gene expression as a means of altering cell fates and generating dominant phenotypes. Development 118 : $401-415$

83. Gustafson K and Boulianne GL (1996) Distinct expression patterns detected within individual tissues by the GAL4 enhancer trap technique. Genome 39: $174-182$

84. Andres AJ and Thummel CS (1994) Methods for quantitative analysis of transcription in larvae and prepupae. In Drosophila melanogaster: Practical Uses in Cell and Molecular Biology. Goldstein LSB and Fyrberg EA, ed. (New York: Academic Press) pp. 565-573

85. Rubin GM and Spradling AC (1982) Genetic transformation of Drosophila with transposable element vectors. Science 218: $348-353$

86. Andres AJ, Fletcher JC, Karim FD and ThummelCS (1993) Molecular analysis of the initiation of insect metamorphosis: a comparative study of Drosophila ecdysteroid-regulated transcription. Dev. Biol. 160: 388-404

87. Karim FD, Guild GM and Thummel CS (1993) The Drosophila Broad-Complex plays a key role in controlling ecdysone-regulated gene expression at the onset of metamorphosis. Development 118: $977-988$ 